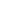




\title{
El reformismo civil moderado y la sátira gráfica: las experiencias de Rochabús y La Olla
}

\author{
Lic. Raúl Rivera Escobar \\ Universidad Nacional Mayor de San Marcos \\ cartonesco@gmail.com
}

\begin{abstract}
Resumen
La sátira gráfica del período de la historia peruana conocido como reformismo civil moderado (19561968) está fundamentalmente representada por dos medios: Rochabús y La Olla. Analiza el carácter documental que ostentan ambas publicaciones, que resumen, en gran parte, las principales incidencias políticas y sociales de aquel período democrático de grandes cambios y expectativas en el país.
\end{abstract}

Palabras clave: democracia, Gobierno civil, sátira, humor, periodismo, golpe militar.

\begin{abstract}
The graphic satire of the Peruvian history period known as "Moderate civil reform" (1956-68) is basically represented by two means: Rochabús and La Olla. Analyzes the documentary nature of both publications, which summarize, largely the main political and social incidents of that democratic period of great changes and expectations in the country.
\end{abstract}

Keywords: Democracy, civil government, satire, humor, journalism, military coup.

\section{Introducción}

Los años 50 y 60 del siglo anterior marcan una progresiva renovación de la vida nacional en todos sus ámbitos.

El historiador Raúl Palacios Rodríguez denomina reformismo civil moderado a esta época que, de manera específica, abarca el segundo Gobierno de Manuel Prado Ugarteche (Fig.1), iniciado en 1956 (con un espacio de interrupción marcado por la Junta Militar de los generales Ricardo Pérez Godoy y Nicolás Lindley) y el primero del arquitecto Fernando Belaúnde Terry (Fig.2), que finaliza en 1968.

El momento se caracterizó, entre muchos otros aspectos, por un notable crecimiento de la economía, estimulado por las políticas estatales favorables al libre mercado, la proliferación de obras públicas de gran envergadura, la creación de nuevas instituciones del Estado, el creciente interés de los gobiernos por el oriente del país, el desarrollo del país como potencia pesquera y el inicio de grandes procesos migratorios de las regiones andinas hacia Lima, motivando la aparición de una problemática derivada de las crecientes demandas insatisfechas de los grupos desplazados establecidos en la capital. 


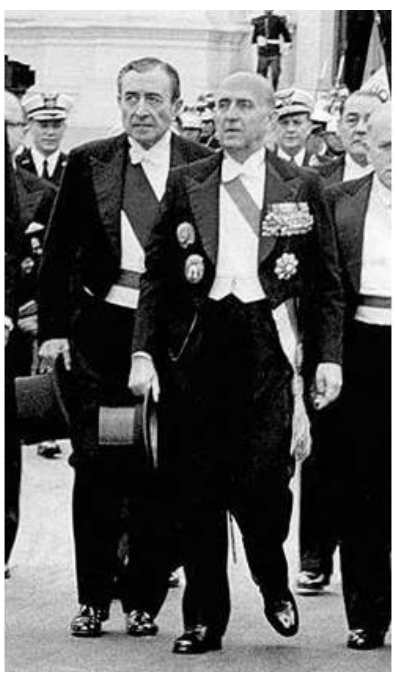

Fig. 1. Manuel Prado Ugarteche en su segundo mandato (1956-1962). Fuente: http.//miguel42oo. blogdiario.com
Por lo demás, tras ocho años de interrupción de la democracia, durante el régimen del general Manuel A. Odría, la llegada al Gobierno de Manuel Prado va a significar no solo el retorno a las libertades públicas (con el voto femenino incluido), sino la aparición de otras formas de entender y proyectar la realidad nacional concebidas por las nuevas figuras políticas, como Fernando Belaúnde o Luis Bedoya Reyes que, junto a las tradicionales, van a dominar en este período.

En medio de ese marco histórico, la libertad irrestricta de prensa, restaurada tras finalizar el régimen de Odría, promovió, entre otros aspectos, el surgimiento de una nueva corriente dentro de la prensa satírico-política nacional.

Así aparecieron Rochabús, una revista crítica al Gobierno de Manuel Prado, editada por el popular periodista Guido Monteverde, y luego La Olla que, dirigida por el reconocido periodista Alfonso Baella Tuesta (quien firmara como el "Director Irresponsable"), sirvió, entre otros fines, para promover la gestión edilicia de Luis Bedoya y fustigar sin tregua al partido aprista.

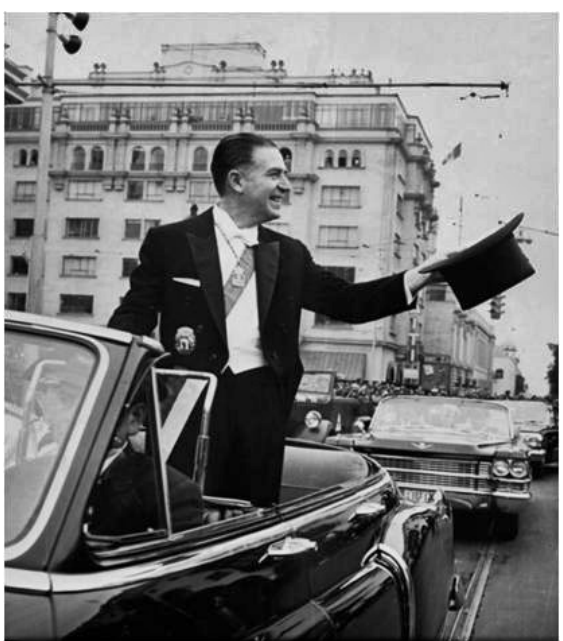

Fig. 2. Fernando Belaúnde Terry durante su primer Gobierno (1963-1968).

Fuente: http.//miguel42oo.blogdiario.com

De ambas publicaciones, festivo retrato del espíritu de la época, emergerá una nueva y talentosa generación de dibujantes de humor, que adquirirá protagonismo en la prensa nacional en los años siguientes, como Julio Fairlie, Pablo Marcos, Víctor Marcos, Guillermo Osorio, Luis Baltazar, Hugo Fernández Vela o Cayo Pinto.

Sin embargo, el abundante material gráfico emanado de la creatividad de estas grandes figuras del lápiz ha dejado de ser solo un enfoque irónico de la realidad del momento, llegando a adquirir una nueva dimensión con el tiempo. Se trata ya de invaluables documentos de época.

De esta manera, el presente trabajo pretende comprobar, a través del estudio del aún abundante material hemerográfico original disponible, el modo en que la narrativa gráfico-humorística realizada en nuestro medio estos años recoge e interpreta el hecho histórico, de la misma manera en que se constituye en reflejo de la vida social y cultural de la época.

\section{Rochabús}

En 1957, a casi un año de la llegada de Manuel Prado al poder, aparece en los kioskos de Lima el primer número del semanario Rochabús.

El nombre de la publicación aludía al término con el cual el ingenio popular había bautizado a los carros rompemanifestaciones que disparaban chorros de agua, a partir del nombre del entonces prefecto de Lima, Temístocles Rocha, hacendado y exsenador por Ica que los trajera a Lima por primera vez. 
Rochabús fue editado hasta 1959 por el controvertido periodista de espectáculos Guido Monteverde (Fig. 3), ya conocido, entre otras cosas, por su leída sección, publicada en el popular diario Última Hora, “¿Qué pasa en radio?”.

Colaboraron en la publicación artistas gráficos destacados, como el arequipeño Guillermo Osorio, que dibujara en los primeros números y luego haría una carrera extraordinaria en importantes medios de prensa (truncada por su temprana muerte); Julio Fairlie, otro historietista arequipeño conocido luego por su personaje Sampietri, y Pablo Marcos, perteneciente a una familia de dibujantes (es hermano de Víctor y Alfredo) y que emigraría luego a Estados Unidos, alcanzando celebridad en la DC Comics y la Marvel.

Junto a ellos, figurarían otros dibujantes regulares del medio, como Ricardo Denegri o Marino Sagástegui.

La crítica abierta al Gobierno de Prado y a los hechos vinculados al manejo del sector hacienda, ocupaba, en gran parte, las páginas del semanario, que tenía entre sus principales e ingeniosas secciones a "Rochabusazo semanal", "Canela fina”, "Pal gato", "Ají con pepa”, "Doña Catona” o "Aprocalipsis", escritas siempre en un tono marcadamente irónico.

La publicación tenía por emblema al “Doctor Rochabús”, un personaje de anteojos, con bigote y cabellos canos, ataviado con traje blanco y corbata michi (Fig.4) que aparecía regularmente como protagonista de sus viñetas principales, que tenían como usuales víctimas a Prado y sus colaboradores en el Gobierno. Prado mismo, bautizado como Manolete, era caricaturizado y aparecía en muchas ocasiones al lado de "Mamani" (Fig.5), un personaje caracterizado como hombre del ande, con chullo y poncho incluidos, y que constituía una especie de personificación alegórica del sufrido pueblo peruano.

\section{Gallo Porras y Beltrán}

Particularmente combatida fue la gestión como premier y ministro de hacienda de Luis Gallo Porras. El también exalcalde de Lima, que era dibujado indistintamente por los artistas de Rochabús con una cresta sobre la frente (en alusión directa a su apellido), debió soportar cerca de un año de agudos comentarios gráficos que se vinculaban con su supuestamente mal manejo de las finanzas públicas, en los días en que empezaba lentamente a introducirse en nuestra economía el modelo neoliberal.

La postura del semanario de Monteverde con respecto a Gallo Porras contrastaría luego con la llegada al premierato de Pedro Beltrán (Fig.6), próspero hombre de negocios y propietario del diario La Prensa quien, encargado también de la cartera de Hacienda (reemplazando a Gallo Porras),

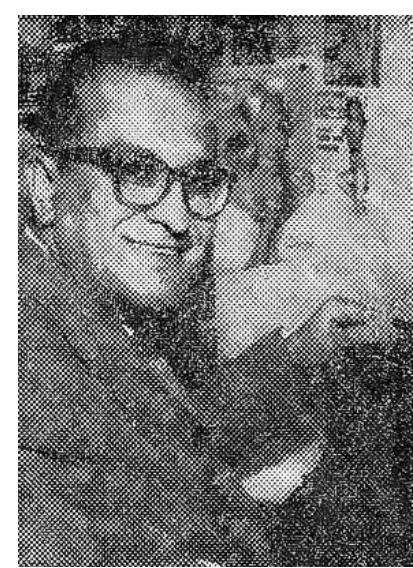

Fig. 3. Guido Monteverde. $\mathrm{La}$ Prensa, 8 de noviembre de 1958.

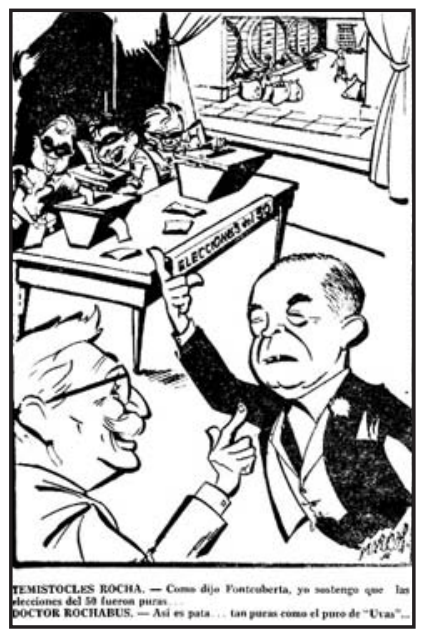

Fig. 4. Rochabús, 11 de marzo de 1959.

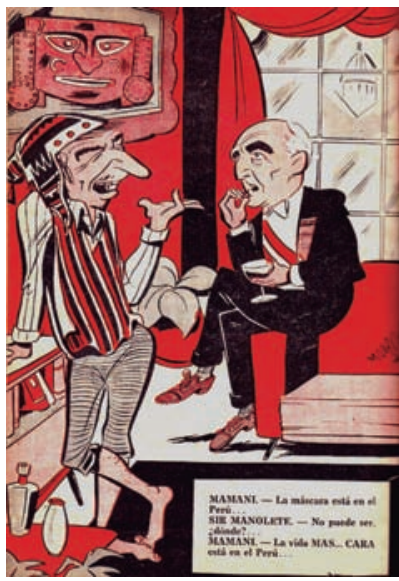

Fig. 5. Rochabús, 1 de julio de 1959. 


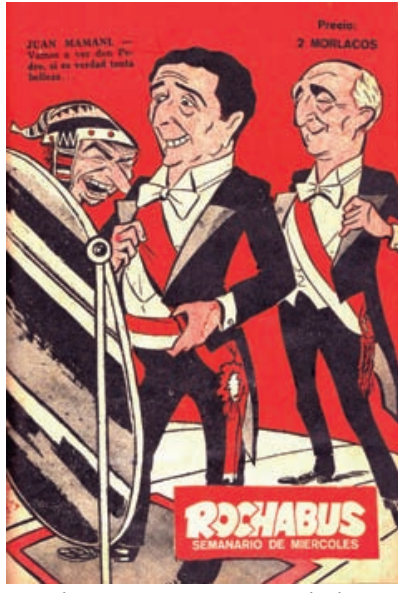

Fig. 6. Rochabús, 22 de julio de 1959.

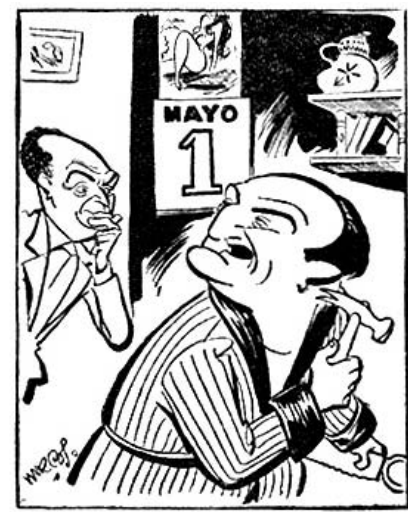

FALLA DE LA TORRE.-Qué tal contradic ción, Ramiro... Hoy he amanecido con unas ganas enormes de ponerme a trabaiar.

Fig. 7. Rochabús, 29 de abril de 1959.

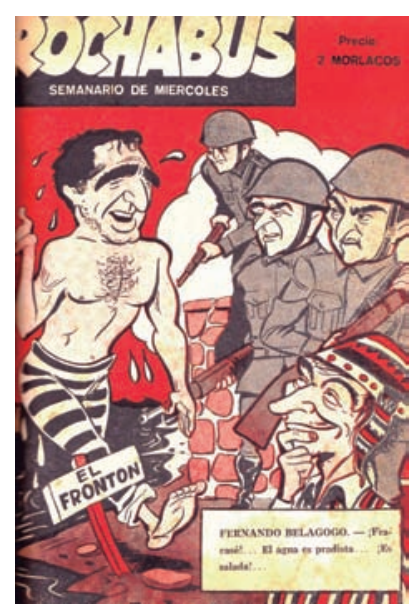

Fig. 8. Rochabús, 17 de junio de 1958 generaba muchas esperanzas, debido a que era un conocido y ferviente partidario de una serie de cambios que permitieran una economía libre y sin trabas.

\section{Antiaprismo}

Por esta época, el APRA (Alianza Popular Revolucionaria Americana) ha retornado ya a la vida política pública, luego de años de persecución que sufriera durante el ochenio de Odría. Atrás han quedado los días en que su fundador, Víctor Raúl Haya de la Torre, vivía confinado en la embajada colombiana en Lima, impedido de salir al exterior por el Gobierno de turno.

El resurgimiento como fuerza política del partido de Haya va a ser combatido también por Rochabús, línea compartida luego por La Olla. El sectarismo del partido, las múltiples acusaciones de demagogia contra sus líderes, como Luis Alberto Sánchez, además del propio Haya (señalado como vago y mantenido por el partido), van a marcar la pauta en ese aspecto (Fig.7).

La convivencia solo va a contribuir a ahondar ese sentimiento contrario de Rochabús al partido de la estrella. Los antiguos enemigos, Haya, Odría y Prado, en medio de una situación insólita en nuestra historia política, van a convivir juntos en democracia, evocando de alguna forma al célebre milagro atribuido a San Martín de Porres, según el cual hizo posible que comieran juntos perro, pericote y gato.

Las caricaturas y los artículos aparecidos en el semanario van a ser así, también, fiel reflejo del decidido rechazo hacia la convivencia que lo caracterizaría durante toda su existencia.

\section{"Belagogo"}

Un tema crucial en estos años es el de la renovación política nacional, a través de la aparición de nuevos líderes.

Un caso emblemático es el de Fernando Belaúnde Terry, joven y brillante arquitecto de familia arequipeña, que incursiona en la política en los años 40, pero que adquiere notoriedad en 1956, tras el recordado manguerazo, que permitiera la inscripción de su partido en el registro electoral.

A Belaúnde, a quien la prensa de humor conocería como "Belagogo", lo vemos ya en Rochabús como uno de los nuevos grandes animadores de la política local, pero también como un personaje controvertido, protagonista de una comentada y frustrada fuga a nado de la isla penal El Frontón (Fig.8), donde estuviera recluido tras ser detenido en 1959 por convocar en Arequipa a un mitin en pleno estado de emergencia.

Gran orador, Belaúnde mostraría, no obstante, para algunos de sus críticos, la imagen de un político impulsivo y 
lenguaraz, que serían sus facetas más explotadas por los dibujantes de humor del período.

\section{La Lima de los 50 en las páginas de Rochabús}

Pero la situación política sirve en muchos casos, también, como pretexto para que Rochabús nos muestre, en un interminable y fascinante desfile, los cambios culturales y de costumbres que empiezan a manifestarse durante los años cincuenta en nuestra sociedad.

La Lima tradicional y conservadora empieza a escandalizarse por la llegada de ritmos musicales nuevos y atrevidos. Las emisoras de radio y las recordadas boites, centros nocturnos característicos de entonces, difunden el mambo, que comienza a despertar un gran interés en las nuevas generaciones.

Así, van a emerger estrellas femeninas de la danza en este nuevo estilo musical, promovido por músicos de fama internacional, como Dámaso Pérez Prado. Mara, Anakaona y Betty Di Roma (Fig. 9) son las figuras nacionales del momento, y su popularidad las llevará a ser las grandes protagonistas de las secciones de espectáculos de diarios y revistas de aquel entonces.

También artistas internacionales aparecen en las páginas de Rochabús. En una época en que la radio empieza a ceder espacio al nuevo medio televisivo, la fama de estos personajes va a verse considerablemente incrementada. Figuras como la cantante y actriz argentina Libertad Lamarque o el cantante y músico norteamericano Nat King Cole visitarán Lima por esos días, en acontecimientos que servirán de marco a diversos chistes gráficos de actualidad política nacional.

\section{El "fantasma" del golpe se hace realidad}

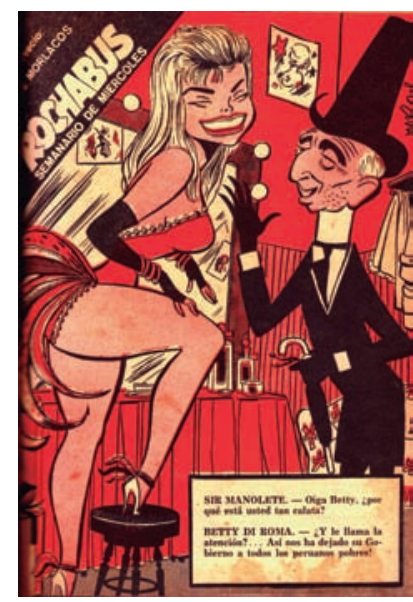

Fig. 9. Rochabús, 1 de abril de 1959.

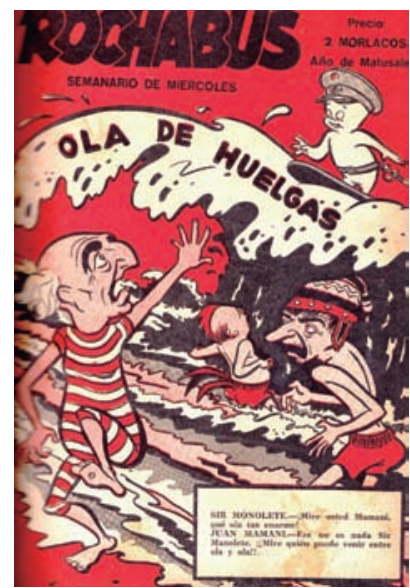

Fig. 10. Rochabús, 26 de noviembre de 1958.

El "fantasma" del golpe había siempre rondado el régimen de Prado. Era lógico en un país que hacía muy poco había salido de un complicado proceso dictatorial. Los dibujantes del semanario aludían, con mucha regularidad, al tema y solían, incluso, personificarlo muy sarcásticamente, como un pequeño fantasmita ataviado con un quepí militar (Fig.10).

Pero lo que parecía una irónica, aunque inocente, visión sobre el destino del Gobierno de la convivencia se tornó, finalmente, en una amarga realidad.

Tras llevarse a cabo las elecciones de 1962, el ejército como institución, alegando fraude (el cual beneficiaba, aparentemente, al líder del APRA y candidato presidencial Haya de la Torre), interviene expulsando del poder a Manuel Prado.

Se inicia así el Gobierno de la Junta Militar comandada por el general Ricardo Pérez Godoy, que marca una abrupta interrupción del proceso democrático que ya se vivía en el país tras el régimen de Odría.

El período establecido por este Gobierno de facto, en que se ensayaron atisbos de reforma agraria y se enfrentó a los primeros grupos guerrilleros, sería, sin embargo, efímero. Al cabo de un año del golpe, el sucesor de Pérez Godoy, el general Nicolás Lindley, convocaba 


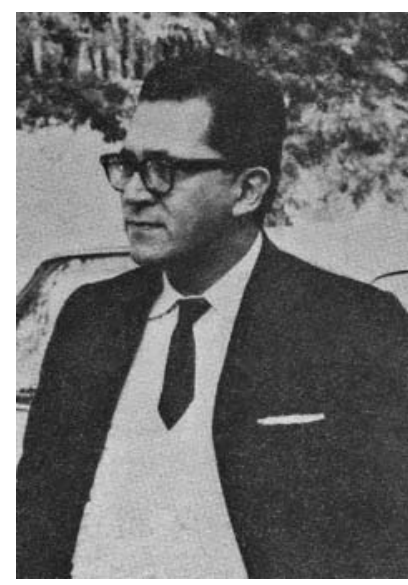

Fig. 11. Alfonso Baella Tuesta, 1963. El Poder Invisible.

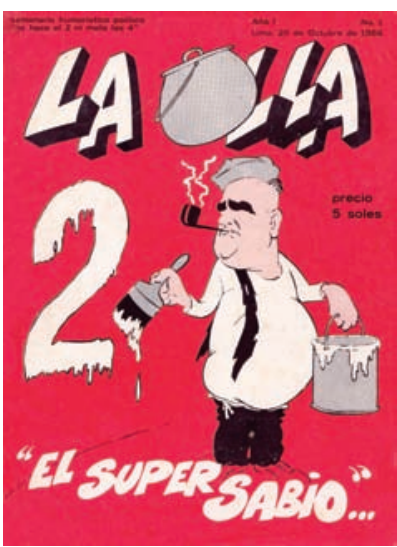

Fig. 12. La Olla, 20 de octubre de 1966. nuevamente a elecciones generales, de las que resultaría triunfador Fernando Belaúnde Terry.

\section{La Olla}

Mientras que Rochabús se convierte en el retrato festivo del Gobierno de Manuel Prado, La Olla va ser, desde 1966, la expresión más representativa de la sátira periodística del primer régimen de Fernando Belaúnde Terry.

La Olla, dueña de una línea progobiernista y conservadora, será dirigida en secreto por el reconocido periodista Alfonso Baella Tuesta (Fig.11), jefe de la página política del importante diario nacional El Comercio, perteneciente al grupo periodístico del mismo nombre, al cual se atribuía la edición del quincenario.

Formando parte de su plana de humoristas, La Olla (Fig.12) va a contar con grandes figuras del lápiz, como el gran Guillermo Osorio, ya bastante conocido y apreciado por sus colaboraciones en las revistas satíricas de los años 50; Hugo Fernández Vela, exponente de una muy estilizada y original propuesta gráfica; Víctor Marcos, excolaborador (como Osorio) de Rochabús y en una línea muy cercana al arte de Vela; Nayo Borja, luego habitual dibujante de El Comercio; Luis Baltazar, Cayo Pinto y Monky (Hernán Bartra), entre otros.

Pero el verdadero dibujante estrella de La Olla va a ser, desde los primeros números, Osorio, autor de su llamativo logotipo y de magníficos trabajos de humor que ocuparán importante espacio en las páginas del quincenario. Alternando en ocasiones con Hugo Fernández Vela y Monky, Osorio va a ser el autor de la mayoría de sus más hilarantes y recordadas carátulas.

Al lado de muchas secciones ocasionales, algunas se mantendrán a lo largo de gran parte de la existencia de La Olla, como "Epistolario de Fray Dique", "Agencia Papayumbus", "Boquillazos", "Los coloquios de Papaya", "El maravilloso país de los Inkas" o "Fernand... él”, que hacía alusión (haciendo un juego de palabras, a partir del nombre de un popular actor cómico francés), en un tono bastante indulgente, a las andanzas del carismático presidente Belaúnde.

\section{El Gobierno de Belaúnde y las trabas en el Parlamento: la coalición APRA-UNO}

El arquitecto y docente universitario Fernando Belaúnde Terry, rostro emblemático de una nueva generación de dirigentes políticos nacionales, había llegado al Palacio de Pizarro tras vencer en los comicios generales de 1963, convocados por la Junta Militar gobernante. Su partido, Acción Popular, va a cogobernar con la Democracia Cristiana, dirigida por un prominente y controvertido líder político: Héctor Cornejo Chávez.

Desde un primer momento, Belaúnde tuvo que enfrentar, como un grave obstáculo a sus actos de Gobierno, a la mayoría de la coalición APRA-UNO (Unión Nacional Odriísta) en el Congreso. Era esta una alianza que se había formado por conveniencia política, luego del insólito acercamiento entre Víctor Raúl Haya de la Torre y el exdictador Manuel A. Odría, en otros tiempos, perseguido y perseguidor, respectivamente. 
La intransigencia de la mayoría parlamentaria se expresó en la oposición a una serie de reformas solicitadas por el ejecutivo, a lo que se sumó el, luego habitual, "deporte" congresal de interpelar a los ministros de Estado, quienes frecuentemente terminaban siendo censurados.

Abiertamente irresponsable y guiada por mezquinos intereses partidarios, la oposición del Congreso estuvo personificada en las figuras del líder aprista Armando Villanueva, presidente de la Cámara de diputados y la del presidente del Senado, el rico hacendado Julio de la Piedra, de tendencia odriísta.

Y, como era de suponerse, ambos personajes serían inmortalizados a través de la sátira gráfica. Osorio dibujaría en La Olla las divertidísimas viñetas de "Los hermanos Picapiedra" (Fig. 13), mostrándolos en toda su cavernaria expresión.

Allí, ataviados de trajes prehistóricos al estilo de los famosos personajes de Los Picapiedra (serie animada americana de los estudios HannaBarbera, de la que tomaban el nombre), aparecían frecuentemente haciendo de las suyas, aunque, en ocasiones, cayendo víctimas, también, de sus maquiavélicas jugadas políticas.

\section{La Olla contra el APRA}

El antiaprismo, desarrollado previamente en publicaciones festivas como Rochabús o la efímera Zamba Canuta (dibujada por Osorio), es alentado también en La Olla, que dedica parte significativa de sus contenidos a ridiculizar la imagen de Haya de la Torre y su partido.

Apodado como "Papaya” (Fusión de papá y Haya) por el medio, el jefe del aprismo va a ser la figura principal de picantes tiras como "Papayumbus" (Unión de papaya y Columbus, agencia de noticias del aprismo continental) o "Los coloquios de Papaya” (Fig. 14), donde se le presenta repetidamente como un individuo sin oficio conocido y mantenido por el partido.

El propio Luis Alberto Sánchez, connotada figura del APRA, va a ser caricaturizado desde su posición de político, pero también desde la de rector de la Universidad de San Marcos (cargo que ejerciera hasta en tres períodos), acusándosele de actos de autoritarismo y corrupción, que incluían el hacer empleo de métodos non sanctos en las elecciones internas para el decanato de la facultad de Letras.

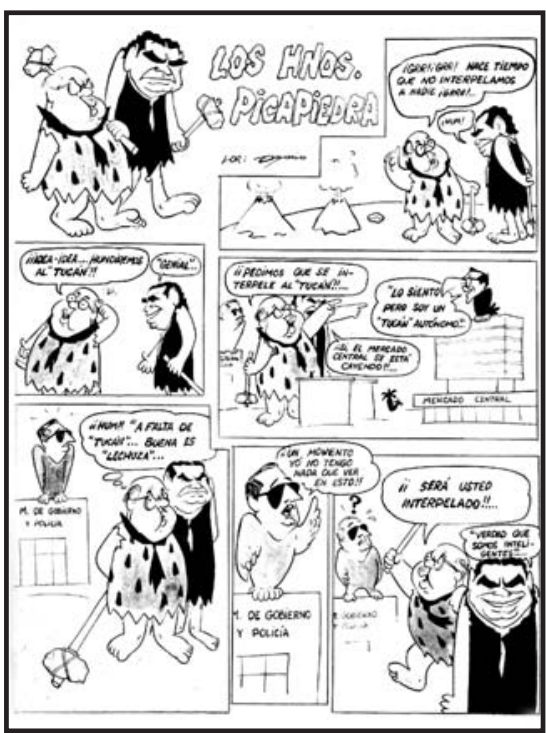

Fig. 13. La Olla, 20 de octubre de 1966.

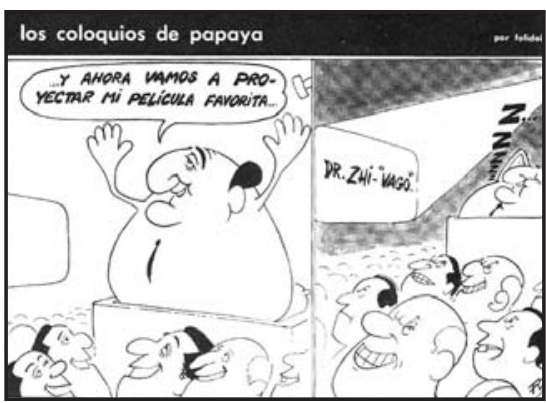

Fig. 14. La Olla, 3 de noviembre de 1966.

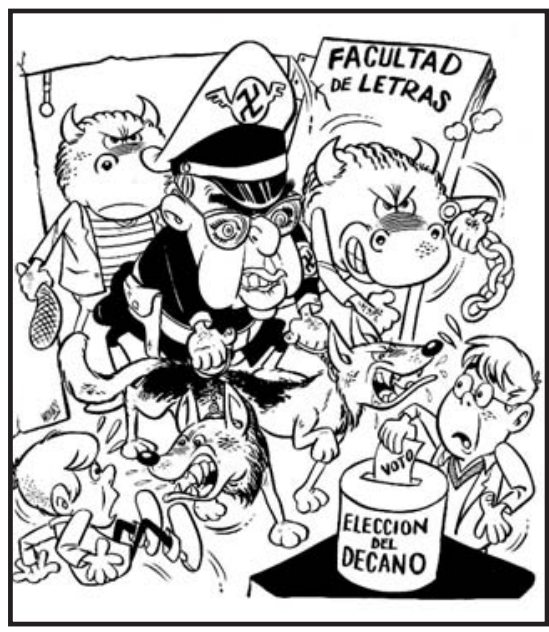

Fig. 15. La Olla, 6 de abril de 1967. 


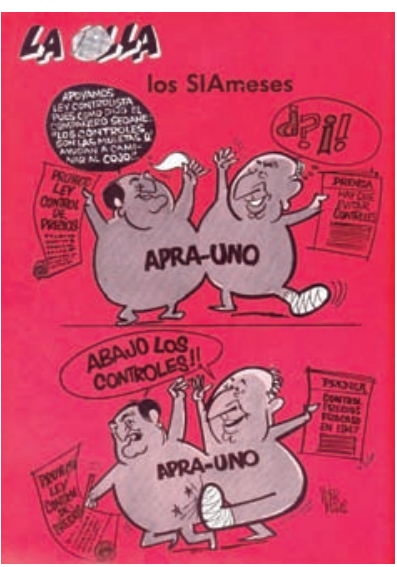

Fig. 16. La Olla, 16 de febrero de 1967.

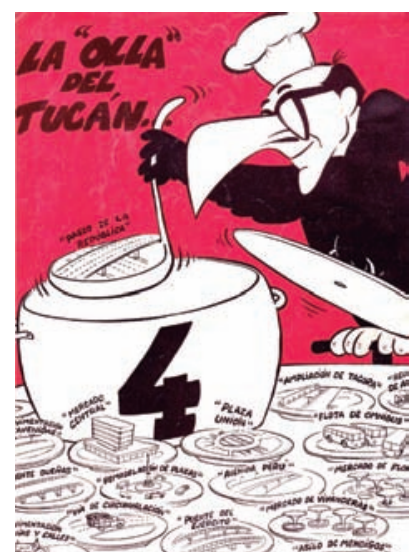

Fig. 17. La Olla, 20 de octubre de 1966.

Era muy conocido que el famoso dirigente aprista llegaba a las instalaciones de la flamante ciudad universitaria de San Marcos precedido por una jauría de feroces perros de ataque, tal como nos lo muestra Monky en uno de sus acertadísimos dibujos para el medio, donde Sánchez aparece ataviado como un amenazante oficial nazi (Fig.15).

Las críticas de la revista hacia la agrupación política de la estrella adquieren una nueva dimensión al aliarse con la Unión Nacional Odriísta, cuyo polémico líder natural, el general Manuel A. Odría, pasaría a ser también blanco habitual de mofas. Era usual que los caricaturistas lo dibujaran siempre con un pie vendado, aludiendo a un accidente sufrido por Odría, según se decía, durante una cita concupiscente.

La cercanía entre Haya y su antiguo enemigo va a encender, particularmente, el espíritu crítico del quincenario, llevando a sus artistas a dar originales muestras de creatividad, como las de Víctor Marcos, quien en determinado momento llega a representar gráficamente a ambos personajes unidos como hermanos siameses (Fig. 16).

\section{Elecciones municipales: Bedoya vs. Grieve}

En 1963, en uno de sus más aplaudidos actos de Gobierno, Belaúnde convocaría en todo el país a elecciones para alcaldes, luego de muchos años de estar vigente entre los gobernantes de turno la práctica de elegir "a dedo" a las autoridades municipales.

Aquel año, la Democracia Cristiana, aliada con Acción Popular, va a lanzar como candidato a la alcaldía de Lima a otro político nuevo, abogado, personaje hábil y carismático, conocido por su buen ánimo y su gran sentido del humor: Luis Bedoya Reyes.

La Olla va a ser una especie de "caja de resonancia” de la postura favorable de la opinión pública en relación a Bedoya. Elegido por primera vez como alcalde de Lima en 1963, llevó a cabo una exitosa gestión, recordada por una serie de importantes obras públicas, como el nuevo Mercado Central, el Paseo de la República o “zanjón”, la Plaza Unión, la vía de Circunvalación, entre otras muchas.

La campaña por la reelección como alcalde de Lima de Bedoya, de 1966, fue ocasión para exhibir sus logros, tal como vemos en una caricatura de Osorio, donde el "Tucán" (su popular apodo, alusivo a su prominente nariz) aparece extrayendo de una olla sus grandes obras (Fig. 17).

El decidido apoyo a Bedoya no se haría esperar de parte de La Olla, que la emprendió contra Grieve a través de sus ácidos escritos y caricaturas.

Si bien algunos analistas de entonces señalarían una ajustada diferencia entre ambos en el debate televisivo que se dio (el primero de su tipo en nuestro medio), lo cierto es que Bedoya terminaría ganando la reelección.

\section{Belaúnde y Punta del Este}

La cuestionada imagen del régimen, debida a su discutible manejo de los asuntos de Gobierno, vino a contrastar esos años con el innegable prestigio de la imagen personal del presidente de la República. 
En ese aspecto, la segunda cumbre de jefes de Estado y de Gobierno de la OEA en Punta del Este (abril de 1967), a la que acudiera como invitado, fue ocasión propicia para sacar a relucir sus bien conocidas dotes como líder y orador.

Belaúnde fue, según muchos, el mejor disertante de aquella cita de presidentes, exponiendo sus argumentos, que eran los del Perú, con firmeza y convicción.

Su participación en aquel histórico evento fue elogiada por muchos medios, entre los que se contaba La Olla, que evocaría la destacada intervención del presidente en una elocuente caricatura de Víctor Marcos, que mostraba a los jefes de Estado asistentes a la cumbre, caracterizados como bailarinas, reconociendo a Belaúnde como la "estrella del show" (Fig. 18).

A su regreso de la importante cita en el conocido balneario uruguayo, Belaúnde ratificaría su gran capacidad para el arte de la elocuencia, agradeciendo espontáneamente las muestras de afecto del pueblo que fuera a recibirlo, a través de un gran y sentido discurso, el cual iniciaba con un vibrante mensaje que ya ha pasado a la historia:

Qué me aplaudes pueblo peruano, si tú mismo has hablado por mis labios.

Qué me aplaudes, si estoy aquí porque tú lo quisiste.

Qué me aplaudes, si fui a Punta del Este porque tú me mandaste.

Y qué laureles me alcanzas, si tú te los ganaste.

\section{El golpe de Velasco y el fin del reformismo civil moderado}

Para 1968, la crisis económica nacional, estimulada por problemas coyunturales, como la sequía en la costa o la merma de divisas por la baja en las exportaciones, llega a niveles preocupantes, teniendo como una de sus más graves consecuencias la devaluación del sol.

Unido al mal manejo económico, se hace evidente la incapacidad del ejecutivo para afrontar la crisis política derivada de sus pugnas con el legislativo. La mayoría opositora APRAUNO en el parlamento, en una actitud desafiante e interesada, se dedica en estos días a impedir cualquier tipo de reforma emprendida por el Gobierno central, siendo moneda corriente la interpelación y la consecuente censura de ministros de Estado.

La amenaza del golpe no era, entonces, algo nuevo para la opinión pública. Tal como otros medios, La Olla, medio en broma y medio en serio, hacía referencia constante a la gravedad de la crisis política que se vivía en el país y ya hablaba, con mucha anticipación, de la posibilidad de que en algún momento se diera un pronunciamiento contra el Gobierno.

Se mencionaba ya, incluso, al propio general Juan Velasco, jefe del Comando Conjunto de las Fuerzas Armadas, como cabeza de la supuesta insurrección, como así lo presenta la portada de la revista del 5 de setiembre de 1968 (Fig. 19).

La caricatura, a cargo de Guillermo Osorio, muestra en primer plano a Velasco, aparentemente instigado por Pedro Beltrán a intervenir ante el "lío de

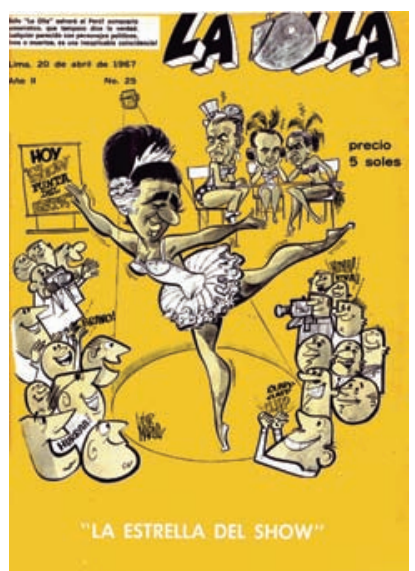

Fig. 18. La Olla, 20 de abril de 1967.

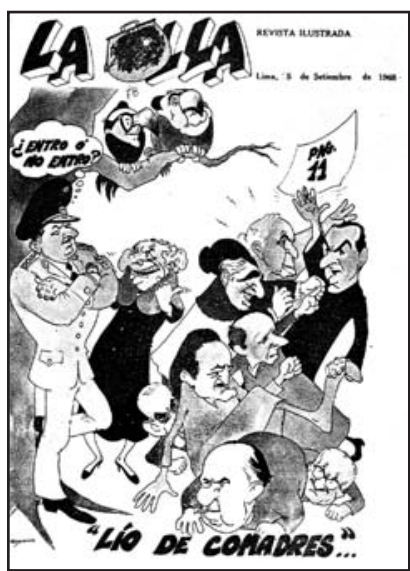

Fig. 19. El Poder Invisible 
comadres" del que participan el presidente Belaúnde; el gerente de la IPC, señor Espinoza; el presidente de la Empresa Petrolera Fiscal, Carlos Loret de Mola; los ministros Carriquiry, Ulloa y Hercelles, junto a los presidentes de las cámaras Towsend y Cox; mientras que, en una rama del árbol, aparecen apartados de la situación Bedoya y Haya de la Torre.

El trabajo de Osorio no hace otra cosa que anunciar, sarcásticamente, los hechos que se darían un mes después. Así, agudizada la crisis por el escándalo de la página once, originado por la sospechosa desaparición del folio 11 del contrato firmado por el Gobierno con la IPC para la explotación de los yacimientos petrolíferos de La Brea y Pariñas, se produciría el golpe de Estado encabezado por el general Juan Velasco Alvarado, el 3 de octubre de 1968.

Y así, de una manera accidentada pero previsible, terminaba sus días aquella etapa de grandes esperanzas frustradas que la historia recordaría, en gran parte, por la incapacidad de los nuevos gobiernos para solucionar problemas nacionales de larga data y el negligente accionar, siempre en beneficio propio, de la clase política nacional.

Era el final anunciado del reformismo civil moderado.

\section{Balance}

A lo largo de las décadas del 50 y 60 del siglo anterior, es de advertir cómo el humor gráfico-político nacional fue convirtiéndose, paulatinamente, no solo en válvula de escape a las situaciones de tensión política y social, siempre habituales en nuestra inquietante realidad, sino en un peculiar, aunque plenamente válido, documento histórico.

Los hechos cotidianos, las modas, los problemas sociales, las intrigas al interior de los gobiernos, los intereses partidarios, las esperanzadoras propuestas de los nuevos políticos, las amenazas de golpe de Estado (calibradas en función de la buena o mala marcha de los regímenes de turno), llenan las páginas de un abundante material hemerográfico que nos permite comprobar el modo en que la narrativa gráfico-humorística producida estos años se constituye en reflejo de la vida nacional de la época.

Pero no solo el registro sistemático de los acontecimientos, de una forma en que la historia oficial muchas veces no recoge, es la gran virtud de la prensa satírica de la época, encarnada en publicaciones como Rochabús o La Olla, sino la manera en que va asumiendo, espontáneamente, el rol de preservar para la posteridad el pensamiento y el sentido crítico de su tiempo.

Así, teniendo en cuenta su doble condición de medio expresivo y comunicacional, el humor gráfico inmortalizado en aquellos medios nos permite formarnos una idea definida acerca de las posturas divergentes de la sociedad local hacia un determinado personaje, asunto o acontecimiento, expresadas a través de una visión despreocupada, a veces apasionada, aunque no por ello privada de auténtica convicción ideológica.

Es la manera en que se veía, directa y crudamente, el día a día y, a la larga, la pieza clave que permitirá a las siguientes generaciones acceder a la interpretación y el consecuente balance de lo vivido en aquel tiempo. 


\section{Referencias bibliográficas}

\section{Fuentes hemerográficas}

Revista humorística Rochabús. Lima. Ediciones años 1958-1959.

Revista humorística La Olla. Lima. Ediciones años 1966-1967.

\section{Fuentes bibliográficas}

Baella Tuesta, A. (1976). El Poder Invisible. 3. ${ }^{a}$ ed. Lima: Editorial Andina.

Basadre, J. (2000). Historia de la República del Perú (1933-2000). Tomo XVIII. Adenda por Raúl Palacios Rodríguez.

Contreras, C. y Cueto, M. (2015). Historia del Perú contemporáneo. 4. ${ }^{\text {a }}$ ed.. Lima: Instituto de Estudios Peruanos.

Zevallos Velarde, O. (2010). Trazos y Risas. Los caricaturistas arequipeños. Arequipa: Cuzzi Editores. 